JUSTICE, EMOTIONS AND COUNTERPRODUCTIVE WORK BEHAVIORS

The Mediating Role of Discrete Emotions in the Relationship between Injustice and Counterproductive Work Behaviors: A Study in Pakistan

\author{
Abdul Karim Khan \\ Suleman Dawood School of Business, Lahore University of Management Sciences (LUMS), \\ D.H.A, Lahore Cantt, 54792, Lahore, Pakistan. \\ Email: abdul.karim@,lums.edu.pk \\ Phone: +924235608040 \\ Samina Quratulain \\ Faculty of Management Studies, University of Central Punjab, \\ 1 - Khayaban-e-Jinnah Road, Johar Town, Lahore, Pakistan. \\ Email: samina.quratulain@ucp.edu.pk
}

Phone: +92 4235880007

Jonathan R. Crawshaw

Aston Business School, Aston University, Aston Triangle, Birmingham, B4 7ET, UK.

Email: j.r.crawshaw2@aston.ac.uk

Phone: +44 1212043130 
JUSTICE, EMOTIONS AND COUNTERPRODUCTIVE WORK BEHAVIORS

The Mediating Role of Discrete Emotions in the Relationship between Injustice and Counterproductive Work Behaviors: A Study in Pakistan

\begin{abstract}
Purpose - Our study explores the mediating role of discrete emotions in the relationships between employee perceptions of distributive and procedural injustice, regarding an annual salary raise, and counterproductive work behaviors (CWBs).

Design/methodology/approach - Survey data were provided by 508 individuals from telecom and IT companies in Pakistan. Confirmatory factor analysis, structural equation modeling and bootstrapping were used to test our hypothesized model.
\end{abstract}

Findings - We found a good fit between the data and our tested model, and partial support for our hypotheses. As predicted, anger (and not sadness) was positively related to aggressive CWBs (abuse against others and production deviance) and fully mediated the relationship between perceived distributive injustice and these CWBs. Against predictions, neither sadness nor anger was significantly related to employee withdrawal.

Implications - Our findings provide organizations with an insight into the emotional consequences of unfair HR policies, and the potential implications for CWBs. Such knowledge may help employers to develop training and counseling interventions that support the effective management of emotions at work. Our findings are particularly salient for national and multinational organizations in Pakistan.

Originality/value - This is one of the first studies to provide empirical support for the relationships between in/justice, discrete emotions and CWBs in a non-Western (Pakistani) context. Our study also provides new evidence for the differential effects of outward/inward emotions on aggressive/passive CWBs. 
JUSTICE, EMOTIONS AND COUNTERPRODUCTIVE WORK BEHAVIORS

The Mediating Role of Discrete Emotions in the Relationship between Injustice and Counterproductive Work Behaviors: A Study in Pakistan

\section{Introduction}

Counterproductive work behaviors (CWBs) are either aggressive (e.g. production deviance and abuse against other) or passive (e.g. employee withdrawal and failing to follow instructions) employee behaviors aimed at harming the current organization and/or its employees (Fox, Spector, \& Miles, 2001). The interest in CWBs has continued to grow as more evidence emerges as to their potential detrimental effects on both employers (e.g. Jensen, Opland, \& Ryan, 2009) and employees (e.g. Aubé, Rousseau, Mama, \& Morin, 2009). Indeed, such deviant behaviors have been shown to predict reduced productivity, higher turnover rates, lower employee commitment and ultimately organizational failure (e.g. Penny \& Spector, 2005; Jones, 2009).

Although the impact of employee injustice perceptions on CWBs is also fairly well established (e.g. Ambrose, Seabright, \& Schminke, 2002), to date, there is still a paucity of academic work attempting to explain this relationship (El Akremi, Vandenberghe, \& Camerman, 2010). Some interesting, and potentially useful, research has begun to explore the role of discrete emotions (e.g. Barclay, Skarlicki, \& Pugh, 2005; Fox et al., 2001). Influenced by affective events theory (e.g. Weiss \& Cropanzano, 1996), which itself is drawn heavily from the cognitive appraisal model of emotions (see Lazarus, 1991a), such studies propose that CWBs are an employee's behavioral response to the negative emotions (e.g. anger, shame, guilt) that result from a specific and meaningful unfair/unfavorable event, such as a layoff decision (see Barclay et al., 2005).

Extant empirical research is limited, however. First, it provides conflicting evidence for the relative importance of distributive, procedural and interactional justice in predicting emotions, with more recent research countering the findings of seminal work into equity 
theory (e.g. Adams, 1965; Homans, 1961) by proposing (and finding support for) a greater role for procedural and interactional justice (Barclay et al., 2005; Krehbiel \& Cropanzano, 2000; Weiss, Suckow \& Cropanzano, 1999). Second, it has tended to use composite 'overall' measures for emotions (Fox et al., 2001; Barclay et al., 2005), thus limiting our understanding of which specific, discrete, emotions may explain the relationship between injustice perceptions and CWBs. Third, extant field research is limited in its contextual scope. Fox et al. (2001) is rather context neutral and Barclay et al. (2005) is focused on the very specific event of a lay-off decision. Layoff events are special circumstances because they sever the relationship between employer and employee and may be more likely to lead to CWBs as a result. Finally, despite empirical evidence suggesting that injustice judgments and their relationship with emotional and behavioral outcomes may not be culture free (Rego \& Cunha, 2010), prior research has been dominated by 'Western' US/European samples (see Greenberg, 2001a).

We thus aim to contribute to the extant literature in four important ways. First, we draw on the cognitive appraisal model of emotions (Lazarus, 1991a) to explore the differential main effects of distributive injustice and procedural injustice ${ }^{1}$, in relation to a pay raise decision, on employee negative emotions. Distributive injustice refers to the perceived inequity of one's pay raise, and procedural injustice the perceived unfairness of the procedures and processes followed to make the pay raise decision (Cropanzano \& Greenberg, 1997). Second, we investigate the differential mediating effects of sadness and anger on the relationship between injustice judgments and three CWBs - withdrawal, production deviance

\footnotetext{
${ }^{1}$ It is important to note that we did not include interactional justice in our study. There were two reasons for this. First, according to Beugré (2007), in high power distance cultures, the relationship between employees and managers may take a highly paternalistic form and deference to authority figures may be considered as a normal way of dealing with supervisors. We were concerned that in asking participants to answer very sensitive questions regarding their supervisors we may promote spurious findings or non-response. Second, our research design focused on emotions experienced immediately after the announcement of annual salary raise and commonly interactional justice calculations come into play some time after the allocation process. Hence, at the time of the salary raise announcement, and data collection, interactional justice perceptions may not yet have been effectively formulated.
} 
and abuse against others - and thus heed Lee and Allen's (2002) call for more research that explores the effects of specific discrete emotions on important organizational variables. Third, as a counterpoint to Barclay et al.'s research on layoff decisions, we investigate employee CWBs in response to a pay raise decision, an event where the relationship between employer and employee is expected to continue in the future. Finally, we extend our research into a more collectivist, high power distance culture - Pakistan (Hofstede, 1980). In such contexts, the maintenance of group harmony and deference to authority may be more highly valued and aggressive emotional and behavioral reactions to perceived injustices more socially unacceptable (see Beugré, 2007; Khilji, 2002). By conducting our study in Pakistan, we provide essential empirical evidence regarding the transferability and generalizability of emotion-orientated research into organizational injustice and CWBs (Rotundo \& Xie, 2008).

\section{Cognitive Appraisal and Organizational Injustice}

The cognitive appraisal model defines emotions as, "ways of apprehending states of the world that have significance for personal well-being" (Lazarus, 1991a, p.89). In short, emotions are our response, and govern our actions, to the losses or gains we experience in meaningful events. More specifically, Lazarus (1991a; 1991b) describes this cognitive appraisal as a two stage process: a primary appraisal where one assesses the core meanings of the event/experience (e.g. what are the gains and losses emerging from this event?) and a secondary appraisal where one assesses the appropriate actions required to cope and respond. Thus the primary stage is said to not only involve an evaluation of gains and losses but also whether these gains and losses are meaningful, or as Lazarus terms this - goal relevant. If an event lacks personal meaning (goal incongruence) no emotional response will emerge whatever the outcome of the event. The secondary stage is more concerned with the 
JUSTICE, EMOTIONS AND COUNTERPRODUCTIVE WORK BEHAVIORS

assignment of blame for one's emotional state and what subsequent actions may help restore personal well-being (e.g. getting angry and seeking retribution).

Importantly, this cognitive appraisal model may help explain why different individuals vary in their emotional reactions to the same event. Specifically, Lazarus (1991a) identifies a number of core relational themes that relate to specific emotional responses. For example, anger is said to be a natural reaction to a specific situation where one has felt threatened, harmed or slighted. In anger, the allocation of blame to a specific agent is essential (Lazarus, 1991a; 1991b). Sadness, on the other hand, is said to be one's natural reaction to events where there are feelings of loss and helplessness. For sadness, no specific agent is identified and held responsible for the loss. Indeed, Lazarus argues that if one were able to blame an external agent for their loss, the emotional response would be anger and not sadness. Importantly, he elucidates further, proposing that it is, "possible for attributions and control, therefore appraisals of blame, to change from moment to moment as the person grieves over the loss" (Lazarus, 1991b, p. 829-830). Consequently the emotional response would also change, either from sadness to anger or vice versa (Lazarus, 1991a; 1991b). Increasingly justice researchers have been drawing interesting, and potential useful, parallels between theoretical developments in organizational justice and the cognitive appraisal model of emotions. In particular, a number of recent studies have applied Weiss and Cropanzano's (1996) affective events theory, and found good support for an interaction effect between an individuals' perceived outcome favorability, in regards to a specific meaningful event, and procedural (or the fairness of the decision-making process - Leventhal, 1980) or interactional (the fairness of the decision maker - Bies \& Moag, 1986) justice when predicting a variety of discrete emotions (e.g. Barclay et al., 2005; Krehbiel \& Cropanzano, 2000). Drawing parallels with fairness theory (Folger \& Cropanzano, 2001), such research proposes that individuals' judgments of outcome favorability reflect Lazarus' (1991a) primary appraisal 
JUSTICE, EMOTIONS AND COUNTERPRODUCTIVE WORK BEHAVIORS

of the event; that is the assessment of one's losses/gains. Perceptions of procedural or interactional justice reflect more secondary appraisals of blame and accountability, where low procedural or interactional justice allows one to externalize and allocate blame for one's losses (Krehbiel \& Cropanzano, 2000). Thus, anger will be predicted by a situation where both the outcome is seen as unfavorable (primary appraisal) and procedural or interactional justice is low (secondary appraisal).

Although useful, these studies are not without their potential limitations. First, they significantly downplay the role of distributive injustice in predicting emotions and, in particular, in Lazarus' (1991a) secondary appraisal process. In line with fairness theory, procedural justice and interactional justice are viewed as providing the key sources of information regarding the allocation of blame and responsibility for outcomes (Folger \& Cropanzano, 2001) - the secondary appraisal process. However, this is counter to much of the early justice research on inequity (distributive injustice) that proposed, and found consistent empirical support for the link between perceived inequity and a range of emotions including anger, sadness, depression, guilt and more composite measures of negative and positive emotions (e.g. Adams, 1965; Chabat \& Slusarczyk, 2005; Fox et al., 2001; Homans, 1961; Spreecher, 1992; 1986).

Second, there is a lack of clarity regarding the role of injustice perceptions in Lazarus' (1991a) primary appraisal process. The studies described above propose outcome favorability as the key mechanism or assessing gains and losses in the primary appraisal process. Although there is some conceptual overlap between the favorability and fairness of outcomes, these are two distinct constructs. Unfavorable outcomes may be fair/equitable and unfair/inequitable outcomes may be favorable (e.g. Adams, 1965). That said, there has been a considerable blurring of the boundaries between unfavorable and unfair outcomes throughout the justice literatures (see Greenberg, 2001b), an issue not helped by statements such as those 
by Barclay et al. (2005) proposing that, "unfavorable distributive outcomes are not the only facet of fairness that can trigger an appraisal"' (p. 631). We would contend that perceptions of unfavorability regarding outcomes are not necessarily the same as perceptions of unfairness regarding outcomes.

However, it is fairly well established in the justice literatures that all three justice dimensions are in some way an assessment of desirable/goal relevant outcomes; a point later recognized by Barclay et al. (2005). Distributive justice is focused on economic outcomes whilst procedural and interactional justice on those that are more socio-emotional in nature. The 'group value' model of justice suggests that the receipt of fair processes (procedural and interactional justice) may confirm one's respect and standing within the social group - thus meeting important socio-emotional goals (for reviews see Cropanzano \& Greenberg, 1997). As such, all three dimensions of justice may be important in the primary appraisal stage. We thus extend prior research by proposing that distributive, procedural and/or interactional justice may all play a dual role. First, they all contain goal relevant outcomes and are potentially central to assessing one's gains or losses from a meaningful event (primary appraisal process). Second, they may all provide sources of evidence for making judgments regarding blame for one's loss and one's appropriate response (secondary appraisal process).

\section{Injustice in Pay Raise Decisions Predicting Negative Emotions - Anger and Sadness}

Pay and pay raise decisions at work hold significant meaning for individuals. Indeed, pay and pay raise decisions may be goal relevant in both economic (income/lifestyle needs, career goals, social status) and/or socio-emotional (self esteem, efficacy, ego enhancement) terms. In line with our review above, unfair outcomes (distributive injustice) and procedures (procedural injustice), in relation to a salary raise decision, are thus goal incongruent, and should predict negative emotional responses. 
JUSTICE, EMOTIONS AND COUNTERPRODUCTIVE WORK BEHAVIORS

The present study focuses on the discrete negative emotions of anger and sadness. A focus on anger and sadness allowed us to compare the different relationships between injustice perceptions and both an 'outward-focused' (Tangney \& Dearing, 2002), 'approach-oriented' (Harmon-Jones \& Sigelman, 2001) emotion (anger) and an 'inward' (Tangney \& Dearing, 2002), passive emotion (sadness). It also allowed us to explore the differential effects of these two emotions on our CWBs. Importantly, previous research suggests that individuals may either react with anger or sadness depending on their ability to attribute blame for their losses (e.g. Keltner, Ellsworth, \& Edwards, 1993), suggesting a close link between these two specific emotions. Anger has been the focus of much justice research (e.g. Beugré, 2005), with many suggesting it is the major emotion which is aroused in response to felt injustice (e.g. Folger, Cropanzano, \& Goldman, 2005). Sadness, on the other hand, is a much overlooked construct within the justice literature. Given its potential close connection with feelings of anger, and the burgeoning research on justice and the related construct of happiness at work (see Cropanzano, Stein, \& Nadisic, 2011), this is perhaps a surprising oversight.

Anger. The core relational themes for anger are a demeaning offence against me and mine (Lazarus \& Cohen-Charash, 2001). Its provocation is a personal slight or insult and thus an injury to one's ego identity (Lazarus, 1991a; 1991b). In anger, blame is also needed and someone must be accountable for the offence. In line with our earlier discussion, we therefore propose that either distributive injustice and/or procedural injustice perceptions, in relation to a pay raise decision, may act both as a personal slight, insult and threat to ego identity, and as a source of information for making blame attributions regarding this unfairness. As such, distributive injustice and/or procedural injustice, regarding a pay raise decision, should predict an anger response.

Prior justice research provides good empirical support for these propositions. Early equity research proposed, and found consistent evidence, for a significant relationship 
JUSTICE, EMOTIONS AND COUNTERPRODUCTIVE WORK BEHAVIORS

between inequity (distributive injustice) perceptions and anger (e.g. Adams, 1965; Homans 1961; Spreecher, 1992, 1986). Research exploring the link between procedural injustice and anger is rather less well established. However, in experimental settings, Van den Bos and Miedema (2000) found that when participants were denied the opportunity to voice their opinions (procedural injustice) they experienced negative emotions like anger and resentment. Similar findings were also reported by Van den Bos (2001a) and Mikula, Scherer, and Athenstaedt (1998). The following hypotheses are thus proposed:

Hypothesis 1a: There is a positive relationship between employee perceptions of distributive injustice, in relation to a salary raise decision, and employee anger Hypothesis $1 b$ : There is a positive relationship between employee perceptions of procedural injustice, in relation to a salary raise decision, and employee anger

Sadness. In contrast, the core relational theme for sadness is irrevocable loss. Felt "helplessness or lack of control, is thus the goal incongruent event that produces sadness" (Lazarus, 1991b, p. 829). In the case of sadness, no specific agent is held accountable for the loss. Thus we propose that perceptions of distributive injustice and/or procedural injustice, regarding a salary raise decision, may lead to feelings of felt 'helplessness' in terms of attaining long term economic and/or socio-emotional goals. Such helplessness may thus in turn lead to feelings of sadness.

In particular, sadness may emerge when the exact source of injustice is unknown, and thus the allocation of blame is difficult. Agent-systems theory suggests that injustices may be felt from multiple sources within organizations - both from the system and from specific agents of that system (Rupp \& Cropanzano, 2002). Uncertainty regarding the exact sources of felt injustices in relation to one's pay raise may lead to greater feelings of helplessness 
JUSTICE, EMOTIONS AND COUNTERPRODUCTIVE WORK BEHAVIORS

regarding the fairness of future pay and pay raise decisions; and ultimately therefore sadness. Sadness may also be more likely when individuals have experienced (perhaps many) prior injustices within the employment relationship and expectations of fair treatment are low. In line with notions of learned helplessness (e.g. Seligman, 1975), in such situations, experiences of further injustices may lead to a more embedded sense of helplessness and hopelessness that one's situation (losses) will ever change.

Sadness may also be a particularly salient emotional response to injustice in a more collectivist context such as Pakistan. Collectivist cultures tend to emphasize the maintenance of group harmony rather than personal gain. Thus injustice in a pay raise decision may lead to sadness (rather than anger) because acting out one's anger and retaliating may be less socially acceptable.

To date, however, few studies have examined sadness as an emotional response to either distributive or procedural injustice. That said, Mikula et al. (1998) reported that sadness may follow feelings of anger when individuals react to an unfair (distributive injustice) event. Van den Bos (2001b) also found that individuals not given voice in decision-making (procedural injustice) reported greater sadness than those who were (see also Hegtvedt \& Killian, 1999). The following hypotheses are therefore proposed:

Hypothesis 2a: There is a positive relationship between employee perceptions of distributive injustice, in relation to a salary raise decision, and employee sadness Hypothesis 2b: There is a positive relationship between employee perceptions of procedural injustice, in relation to a salary raise decision, and employee sadness 
JUSTICE, EMOTIONS AND COUNTERPRODUCTIVE WORK BEHAVIORS

\section{Injustice and CWBs: The Mediating Roles of Anger and Sadness}

We focused on three discrete CWBs, abuse against others, production deviance and withdrawal. We posit that abuse against others and production deviance as examples of aggressive CWBs, whereas withdrawal is more passive in nature. Abuse against others refers to behaviors directed towards co-workers and others where the motive is to harm them physically and/or psychologically through threats, nasty comments and undermining their performance. Production deviance is purposeful failure to perform job tasks in an efficient way. It includes acts like deliberately working slowly, working incorrectly, purposefully failing to follow instructions of management and is an attempt by the individual to interrupt efficient organizational functioning (see Spector et al., 2006). Although production deviance may be considered a more passive, displaced form of aggression, it is still thought to be caused by the same emotional reactions as that of sabotage - and thus ultimately to be an aggressive act (Neuman \& Baron, 1997).

Withdrawal, on the other hand, is thought to be a more benign, passive and nonretaliatory form of CWBs. Thus withdrawal is more about an individual's attempts to either physically or psychologically escape an unpleasant situation, rather than their seeking to cause any direct harm to the organization and/or its agents (e.g. Spector et al., 2006; Tangney \& Salovey, 1999). Of course, an employee's physical or psychological withdrawal may actually cause significant harm or inconvenience to one's organization or line manager, but importantly this is not the primary motive for such actions.

Anger is a high arousal, approach-oriented emotion and such emotions are particularly associated with aggressive reactions (e.g. Buss \& Perry, 1992; Harmon-Jones \& Sigelman, 2001). The motivations behind getting angry may be associated with the desire for revenge, directing action against the perpetrator, and punishment (Allred, 1999). According to the 'vigilante model' of justice, anger can motivate individuals to right wrongs and deter future 
JUSTICE, EMOTIONS AND COUNTERPRODUCTIVE WORK BEHAVIORS

injustices (Bies \& Tripp, 2002; Cropanzano \& Baron, 1991). Specifically, anger can be directed towards the organization and/or its members, depending on what or who is believed to be responsible for the felt injustice (Beugré, 2005). We predict, therefore, that anger (and not sadness) will be strongly associated with our two aggressive CWBs - abuse against others and production deviance - and the following hypotheses are proposed:

Hypothesis 3a: Anger, but not sadness, is positively related to employees' abuse against others and mediates the positive relationship between employees' perceptions of distributive and procedural injustice, regarding a pay raise decision, and employees' abuse against others.

Hypothesis 3b: Anger, but not sadness, is positively related to employees' production deviance and mediates the positive relationship between employee perceptions of distributive and procedural injustice, regarding a pay raise decision, and employees’ production deviance.

Sadness, in contrast, is a low arousal, inward focused emotion (Lazarus, 1991b). To date, we are unaware of any published research exploring the relationship between sadness and CWBs. However, low arousal emotions, such as sadness, are said to be more closely associated with less overtly retributive or aggressive behaviors such as physical (absenteeism) and psychological (giving up) withdrawal (e.g. Tangney \& Salovey, 1999; Lazarus, 1991b). We propose, therefore, that sadness (and not anger) will be strongly associated with our passive CWBs - withdrawal, and the following hypothesis is proposed: 
JUSTICE, EMOTIONS AND COUNTERPRODUCTIVE WORK BEHAVIORS

Hypothesis 4: Sadness, but not anger, is positively related to employees' withdrawal and mediates the positive relationship between employee perceptions of distributive and procedural injustice, regarding a pay raise decision, and employees' withdrawal.

\section{Method}

\section{Sample and Procedure}

Participants were 700 employees from five telecommunication and three IT sector organizations located in Islamabad and Lahore, Pakistan. All were employed by medium to large sized organizations of between 500 and 4000 employees. To the best of our knowledge, in all organizations salary raise decisions did not exceed $40 \%$ of employees' base pay.

All questionnaire items were checked for proper wording and some words and statements were rephrased. All items were measured on a 5 point Likert scale. In each organization, the HR department was contacted when seeking permission regarding the administering of the questionnaires. Questionnaires, along with a letter inviting employees to participate and explaining the purpose of survey, were sent to participants 15 days after the announcement of their annual salary raise. Assurances of sufficient English language skills for completing the questionnaire were sought beforehand. After completion, respondents posted the questionnaire to the first author via a self addressed envelope provided. After excluding cases with missing data, a total of 508 usable questionnaires were retained, giving us a final useable response rate of $73 \%$.

\section{Measures}

Organizational justice. We contextualized Colquitt's (2001) justice measure to assess employee distributive and procedural justice perceptions regarding their salary raise. Respondents were asked to rate each question on a five point scale from $1=$ Not at all to $5=\mathrm{A}$ 
great extent. After obtaining the scores of justice perceptions, we reverse coded the items to get the injustice scores.

Distributive justice was measured with four items, "Is your salary raise appropriate for the work you have completed?", "Does your salary raise reflect the effort you have put into your work?", "Does your salary raise reflect what you have contributed to the organization?" and "Is your salary raise justified, given your performance?". A Cronbach $\alpha$ score of .87 gave us confidence in the internal stability of this measure.

Procedural justice was also measured with four items. An earlier study involving two independent samples ( $\mathrm{N}=192$ and $\mathrm{N}=512)$ of Pakistani employees from a range of organizations found that only four of the seven Colquitt (2001) procedural justice items loaded onto a separate factor (Khan, 2009). We thus excluded the 3 cross-loading items, "Have you been able to express your views and feelings during those procedures?", "Have you had influence over the pay raise arrived at by those procedures?", and "Have you been able to appeal the pay raise decision arrived at by those procedures?" from the current study. These items refer to employee voice and influence over decision making (Leventhal's (1980) process control and correctability), decision-making processes that may not be the norm in high power distance cultures such as Pakistan (see Beugré, 2007). It was, therefore, felt justified to exclude these items from the present study. The remaining items were, "Have those procedures been applied consistently?", "Have those procedures been free of bias?", "Have those procedures been based on accurate information?" and "Have those procedures upheld ethical and moral standards?". A Cronbach $\alpha$ score of .79 gave us confidence in the internal stability of this measure.

Anger. Respondents were instructed to indicate that how they felt when they heard about the decision of their last salary raise. For anger, we used seven items from the 10 -item The State-Trait Anger Expression Inventory (STAXI) developed by Spielberger (1988). We 
JUSTICE, EMOTIONS AND COUNTERPRODUCTIVE WORK BEHAVIORS

adapted this instrument to the Pakistani context and dropped three items (I felt like yelling at somebody, I felt like hitting someone and I felt irritated) on the recommendation of a focus group made up of three Pakistani academic professors and five Pakistani managers. Four further items were removed because of high cross-loadings with items from the CWBs scales. The remaining three items were, "I felt mad", "I felt like I was about to explode", and "I felt like banging on the table". A Cronbach $\alpha$ reliability score of .72 gave us confidence in the internal stability of this measure.

Sadness. For sadness, we used four items from positive and negative affect scale (PANAS-X) manual (Watson and Clark, 1994). We removed one item of sadness (I felt downhearted) to improve the internal reliability of the scale. The three remaining items were, "I felt sad", "I felt alone" and "I felt blue". A Cronbach $\alpha$ score of .77 gave us confidence in the internal stability of this measure.

CWBs. CWBs were measured using the scales developed by Spector et al. (2006). Participants were asked to rate on a five-point scale ( $1=$ Never and $5=$ Everyday $)$ the extent to which they had performed the following behaviors in past 15 days. Abuse against others was measured by 15 items. We removed seven items because of high cross-loadings. The remaining 8-item scale included, "Blamed someone else for your own error/mistake", "Made fun of someone's personal life", "Verbally abused someone at work", "Insulted or made fun of someone at work", "Started a useless argument with someone at work", "Made an indecent gesture to someone at work", "Verbally threatened someone at work, but no physically", and "Played/told a mean joke to embarrass someone at work". A Cronbach $\alpha$ score of .85 gave us confidence in the internal stability of this measure. Production deviance was measured by three items, "purposely did your work incorrectly", "purposely worked slowly when it was required to work faster", and purposely failed to follow instructions of seniors". A Cronbach $\alpha$ score of .71 gave us confidence in the internal stability of this measure. Withdrawal behavior 
was assessed with four items, "came to work late without permission", "stayed home from work and told a lie that you were sick", "taken a longer break during work than you were allowed to take", and "left work earlier before the closing hours". A Cronbach $\alpha$ score of .61 gave us some confidence in the internal stability of this measure. Although the measure of CWBs developed by Spector et al. (2006) is composed of five dimensions, we used only three in our study, excluding the scales for sabotage and theft because of low reliability and high cross-loadings respectively. This decision is in line with previous research that has reported very low reliabilities of these measures (e.g. Jensen et al., 2009).

Controls. In order to maintain anonymity, and due to the sensitive nature of questions relating to CWBs, we followed the recommendations of Spector et al. (2006) and limited our collection of demographic data. However, we did control for both organization (worksite) and respondent gender in all of our analysis. Controlling for organization allowed us to control for any contextual effects on employee injustice perceptions and CWBs. Controlling for gender was important as prior research suggests that retaliatory/deviant behaviors at work may be more common in male rather than female employees (e.g. Hollinger \& Clark, 1983). Dummy codes of both organization and gender were thus introduced into our tested models.

\section{Data Analysis}

There were two main stages of our analysis. First, we conducted confirmatory factor analysis (CFA) to check the discriminant validity of our three main measurement scales organizational justice, emotions, and CWBs. Second, structural equation modeling (SEM) and bootstrapping were used to test the overall goodness of fit of our proposed model and to explore the hypothesized relationships between the model variables. All analyses were carried out using the AMOS version 19 (Arbuckle, 1999) software package. 
JUSTICE, EMOTIONS AND COUNTERPRODUCTIVE WORK BEHAVIORS

In line with recommendations, a combination of the chi-square test statistic with corresponding degrees of freedom and statistical significance $\left(\chi^{2}(d f), p\right)$, Comparative Fit Index (CFI) and the Root Mean Square Error of Approximation (RMSEA) were used in both our CFA and model testing (e.g. Hu \& Bentler, 1999). Non-significant chi-square results, CFI scores of above .95 and RMSEA scores of below .06 are said to reflect a good model fit (e.g. Bentler, 1990). To assess the statistical significance of differences between model fit of the nested models we calculated the difference in model chi-square and degrees of freedom, and compared the values with the chi-square distribution (Hu \& Bentler, 1995). Tests for the hypothesized direct and indirect (mediation) effects were carried out using bootstrapping (e.g. Iacobucci, 2008). Five hundred bootstrap re-samples and significance tests based on the biascorrected $95 \%$ confidence intervals were used.

\section{Results}

\section{Confirmatory Factor Analysis}

In all we compared five models. Model 1 contained 3 factors, one containing all the justice items, one with all items of emotions and one with all items of CWBs. Model 2 contained 4 factors, with the items for distributive and procedural justice now loaded onto separate factors. Model 3 contained 5 factors and was the same as Model 2 but with items for sadness and anger now loaded onto separate factors. Model 4 contained six factors was the same as Model 3 but included a two-factor model of CWBs - passive CWBs (withdrawal) and aggressive CWBs (abuse against others and production deviance). Finally, we tested our hypothesized seven-factor model (Model 5). It was the same as Model 3 but with the three CWB constructs (withdrawal, abuse against others, and production deviance) loaded onto separate factors. 
JUSTICE, EMOTIONS AND COUNTERPRODUCTIVE WORK BEHAVIORS

Table 1 reports the fit statistics for each model and its comparison with our hypothesized seven-factor measurement model. Examination of the difference in chi-square statistics highlights the statistically better fit of this seven-factor model (Model 5). A CFI of .94 and RMSEA of .04 also provide further evidence of the goodness-of-fit of this model. Overall, therefore, the results of CFA gave us confidence in the discriminant validity of our seven scales and we proceeded with the testing of our main hypotheses.

\section{Descriptive Statistics}

Table 2 shows the means, standard deviations, and inter-correlations between the main model variables. The values on the diagonal of Table 2 are Cronbach's $\alpha$ reliability scores. It is important to note here that our measures of CWBs and emotions all have fairly low means. Organizational policies and procedures explicitly discourage CWBs and, as such, these acts tend to be low occurring events. Low means are thus to be expected. Indeed, our findings are in line with much of the extant research. For example, Barclay et al (2005) reported a mean of 1.52 on a 5-point scale for inward focused emotions. In their CWBs research, Cohen-Charash and Mueller (2007) reported a mean of 1.39 for interpersonal CWBs and Jensen et al. (2009) found low means for abuse (1.86) and production deviance (1.68). Given the consistency in these (and our) findings, we proceeded with our analysis with confidence. The correlation matrix also highlighted significant relationships between the two emotion constructs (anger and sadness) and between the four dependent variables (CWBs). These additional correlations (covariances) were accounted for when testing our alternative models (Byrne, 2009).

"Insert Table 2 Here" 
JUSTICE, EMOTIONS AND COUNTERPRODUCTIVE WORK BEHAVIORS

\title{
Model Testing
}

We compared two models. First, we tested a main effects model (Model 1) which only predicted direct relationships between our independent variables (distributive injustice, procedural injustice, anger, and sadness) and our CWBs, that is, no mediation paths were included. We then tested our hypothesized model (Model 2) where sadness is predicted to mediate the relationships between distributive/procedural injustice and employee withdrawal, and anger is predicted to mediate the relationships between distributive/procedural injustice and employee abuse against others and production deviance.

\author{
"Insert Table 3 Here" \\ "Insert Figure 1 Here"
}

An examination of the model fit statistics (Table 3) suggests an excellent fit between the data and our hypothesized model $\left(\chi^{2}=831.35(578), \mathrm{p}<.01 ; \mathrm{CFI}=.95 ; \mathrm{RMSEA}=.03\right)$. Although the alternative 'main effects' model (Model 1) was also a good fit of the data, a comparison of the chi-square fit statistics suggests that our hypothesized model is a statistically better fit $\left(\Delta \chi^{2}=22.48(5), p<.01\right)$ (see Table 3). More recent research has suggested such model comparison tests may be overly lenient (Cheung \& Rensvold, 2002), instead recommending the use of bootstrapping techniques when seeking support for mediation models (see Iacobucci, 2008). We thus carried out bootstrapping to test for the indirect effects proposed in our model.

Overall, an examination of the standardized estimates suggests partial support for our tested model. As predicted, distributive injustice was found to be positively related to employee anger $(\gamma=.24, p<.01)$ and sadness $(\gamma=.25, p<.01)$ providing full support for hypotheses 1a and 2a. Against predictions, significant relationships were not found between 
procedural injustice and both anger $(\gamma=.09, n s)$ and sadness $(\gamma=.14, n s)$, thus hypothesis $1 \mathrm{~b}$ and $2 \mathrm{~b}$ were rejected. As predicted, anger was found to be significantly and positively related to abuse against others $(\gamma=.31, p<.01)$ and production deviance $(\gamma=.19, p<.01)$. Significant modification indices were not recommended for a relationship between anger and withdrawal, thus supporting our proposition that anger would not be significantly related to passive CWBs such as withdrawal. The relationship between sadness and withdrawal was non-significant $(\gamma=.08, n s)$. However, again no significant modification indices were recommended for relationships between sadness and production deviance and sadness and abuse against others, again supporting our propositions that sadness would not be significantly related to aggressive CWBs such as production deviance and abuse against others.

As hypothesized, bootstrap analysis found a significant indirect (mediating) effect of anger in the relationship between distributive injustice and employee abuse against others $(\gamma=$ $.04, p<.01)$ and production deviance $(\gamma=.03, p<.01)$. No significant main effects were highlighted between distributive injustice and employee abuse against others and production deviance, when controlling for anger, suggesting anger fully mediates these relationships. Given the non-significant relationship between procedural injustice and anger, a similar relationship between procedural injustice, anger and these CWBs was not found. Overall, partial support is presented for hypotheses 3a-c. Against prediction, sadness was not found to mediate the relationship between distributive and/or procedural injustice and withdrawal, thus hypothesis 4 was rejected.

\section{Discussion}

This research adopted cognitive appraisal theory to explore the mediating role of discrete emotions (anger and sadness) in the relationships between distributive and procedural injustice regarding a salary raise decision, and a number of CWBs; abuse against others, production 
JUSTICE, EMOTIONS AND COUNTERPRODUCTIVE WORK BEHAVIORS

deviance and withdrawal. Overall, our findings provide good support for the tested model. We hereby draw the readers' attention to a number of specific findings and contributions of our research.

First, our results show that it is distributive injustice perceptions, and not procedural injustice, regarding one's salary raise, that may be the more important predictor of negative emotions. While these results are counter to the propositions and findings of recent justice research (e.g. affective events theory - Weiss \& Cropanzano, 1996 and uncertainty management theory - Van den Bos, 2001a), the prominent role of distributive injustice in emotional responses is generally supported in much of the earlier distributive justice research around the emotional responses to inequity perceptions (see Adams, 1965; Homans, 1961). Our findings provide much needed field-based empirical testing of these relationships and, in particular, help fill the current void in research exploring the differential effects of distributive injustice and procedural injustice on both high arousal (anger) and low arousal (sadness) emotions.

Second, we found partial support for the differential effects of anger and sadness on our aggressive (abuse against others, production deviance) and passive (withdrawal) CWBs. As predicted, anger, a high arousal emotion (Buss \& Perry, 1992; Harmon-Jones \& Sigelman, 2001), was found to be positively related to our aggressive CWBs. Sadness, a low arousal emotion, was not. Consistent with cognitive appraisal theory, we also found that anger mediated the relationship between distributive injustice and aggressive CWBs (abuse against others and production deviance). These behaviors may be seen as equity restoration behaviors and also support the vigilante model of justice (Tripp, Bies, \& Aquino, 2007). Production deviance, for example, involves one withdrawing effort so as to achieve the equity balance. Previous studies have tended to be dominated by composite measures of both emotions and CWBs (e.g. Fox et al., 2001), thus limiting our knowledge and understanding of these 
relationships. Our study extends prior research by presenting much needed empirical findings of the specific emotional responses to injustice perceptions and the implications of these different emotions for different, more clearly defined, CWBs.

Finally, our study provides essential empirical testing of these relationships in a new non-Western, Pakistani, context. We felt that Pakistan provided an excellent setting in which to explore the generalizability of these effects. Emotion display rules (such as showing anger) are very much tied up with pervading societal/cultural values and norms (e.g. Geddes \& Callister, 2007). In Pakistan, a largely collectivist and high power distance culture (e.g. Khilji 2002), one may expect the maintenance of group harmony and deference to authority to be dominant organizational norms. As such, expressions of aggressive emotions (anger) and behaviors (abuse against others and production deviance) may be less acceptable. Moreover, the poor economic context of Pakistan (high unemployment and low job security) might also be expected to suppress open expressions of discontent and deviance, for fear of one losing their job and being unable to secure alternative employment (Khilji, 2002). However, the strong and significant effects between distributive injustice, anger and aggressive CWBs in our study, highlight the important emotional component of felt injustice even in this context. Essential empirical evidence highlighting the generalizability of cognitive appraisal theory and the relationships between injustice, emotions and CWBs is thus presented.

\section{Limitations and Future Research Directions}

The contributions of our study should be considered in view of certain limitations, which are presented here as opportunities for future research. We used self-report measures for all variables in our model and thus problems of common method bias are potentially raised. However, we felt the use of self-reports justified by the nature of the variables examined. Emotions, such as anger and sadness, and injustice judgments are clearly best reported by the 
person experiencing them (see Cohen-Charash \& Mueller, 2007; Diener, 2000). Similarly, although it is possible to obtain peer or supervisor reports for CWBs, we again felt that selfreports were more appropriate. First, many of the behaviors assessed would be private and covert and thus extremely difficult for others to observe. Second, there is potential that supervisor ratings may themselves be severely contaminated by the halo/horns effect. Finally, previous studies have shown that self and peer reports significantly converge on many study variables (e.g. De Jonge \& Peeters, 2009). Indeed, results of Harman's single factor test and our descriptive statistics confirm that common method bias was unlikely to be a problem in our sample (Spector, 2006). Our study is also cross-sectional and thus despite our findings supporting cognitive appraisal theory and previous justice research, future research should aim to apply longitudinal designs that may better explore causal effects between these constructs.

We used retrospective self-reports to measure individuals' emotional response to their annual salary raise decision. Although retrospective reports can be problematic (e.g. Robinson \& Clore, 2002), we believe that memory bias may have had minimal effect in our study. Problems of recall accuracy in retrospective reports of emotions are said to stem from two related issues - recency and accessibility (Robinson \& Clore, 2002). First, we did not feel that recency biases may be a particular issue in our study as we measured employee reactions to their salary raise just 15 days after its announcement, thus the time span between the actual event and recall is relatively short. This timeframe is far shorter than many previous field studies that have required respondents to recall their emotional response to events that may have taken place months, maybe up to a year, previously (e.g. Barclay et al., 2005; Chebat \& Slusarczyk, 2005). As all employees were informed of the salary raise decision at the same time we also felt it unnecessary to control for length of time since the event; as had been the case in previous studies (e.g. Barclay et al., 2005). 
JUSTICE, EMOTIONS AND COUNTERPRODUCTIVE WORK BEHAVIORS

Accessibility issues are strongly connected with the valence of the event (e.g. Kihlstrom, Eich, Sandbrand, \& Tobias, 2000) with prior research demonstrating that individuals are better able to accurately recall their emotions and feelings in relation to highly salient experiences (e.g. Fabiani \& Donchin, 1995). For most people pay raise decisions are highly salient, and thus recalling accurately one's emotions and feelings about such unfair events may be less problematic.

Prior research also suggests that inaccuracy in the recall of negative emotions (such as sadness and anger), if anything tends to take the form of an overestimation of one's emotional response to events (e.g. Thomas \& Diener, 1990). An examination of our findings highlights rather low means when it comes to our respondent self-reports regarding their anger and sadness after the pay raise decision. Such findings may provide some evidence that overestimations of anger and sadness in this particular case may not be a problem. We also recognize, however, that future field studies may benefit by controlling for respondent perceptions of outcome valence in their analysis (see also Barclay et al., 2005).

In order to maintain respondent anonymity and thus elicit the most accurate responses possible, we collected a limited amount of demographic data from respondents (see Spector et al., 2006). We felt this may also be particularly pertinent in a context such as Pakistan. First, in Pakistan there is high unemployment and employees are not so open in replying to questions like CWBs for fear they might lose their jobs if they are identified with their responses. Secondly, anger, like CWBs, is a socially undesirable emotion and people may not easily accept that they are feeling angry due to strong societal and religious values. However, future research may seek to collect such information from respondents so that important demographic data may be controlled for in analysis. We also recognize that the future research would be improved by the inclusion of one or two further controls in the analysis, for example, CWBs in the days previous to the event and perhaps certain personality traits. 
JUSTICE, EMOTIONS AND COUNTERPRODUCTIVE WORK BEHAVIORS

Future research may also explore potential moderators of our tested relationships. For example, studies may explore the moderating role of future injustice expectations on the relationship between felt injustice and emotions. It may be that when expectations of justice are low (for example, when previous pay raise decisions had been unjust), felt injustice will lead to feelings of resignation, helplessness, and sadness. However, when justice expectations are high, felt injustice may lead to feelings of frustration and anger. Future studies may also apply more explicitly the multi-foci model of justice and explore the differential effects of agent versus systemic justice. It may be that when the source of injustice is a specific agent, anger is more likely. When the injustice is systemic, there may be greater feelings of helplessness and thus sadness. It may be that the direction of anger is justice different.

Recently, the debate that justice and injustice are two distinct constructs is emerging in justice literature (e.g. Colquitt, Long, Rodell, Halvorsen-Ganepola, 2010). The findings from these studies show that justice and injustice are indeed different constructs like satisfaction and dissatisfaction. Future studies may wish to make this distinction, exploring the implications for emotions and CWBs of both justice and injustice judgments.

Finally, we only focused on two emotions - anger and sadness - and thus our analysis is limited. More specific emotions like resentment (Mummendey, Kessler, Klink, \& Mielke, 1999) may also be related to CWBs in the context of organizational injustice. Alternatively, there has been some interesting work exploring the role of stress in the relationship between injustice perceptions and CWBs (e.g. Krischer, Penny, \& Hunter, 2010). Stress is not just one emotion, but a combination of anger, anxiety, disappointment, and sadness. Whilst the contribution of the present study was specifically about uncovering the role of discrete emotions in explaining the links between injustice perceptions and CWBs, future research may also begin to examine the roles of stress or emotional exhaustion in these relationships. 
JUSTICE, EMOTIONS AND COUNTERPRODUCTIVE WORK BEHAVIORS

\section{Practical Implications}

Despite these limitations a number of important implications for employers are proposed. Previous research has highlighted the negative impact of employee CWBs on organizational effectiveness and performance (e.g. Jenson et al., 2009). Our results suggest that employers may avoid these effects by implementing fair HR policies and procedures. Fair HRM distributes valued rewards and resources equitably through the use of ethical, transparent, consistent, and voice-providing decision-making procedures. It is through such fair HRM that employers can manage effectively the emotional dimension of work, a key antecedent of CWBs.

Given the potential salience of emotions in predicting employee CWBs, employers may also improve the management of emotions at work by providing all employees with emotional intelligence training and counseling. Emotional intelligence is described as a set of abilities that refer in part to how effectively one deals with emotions both within oneself and others (Salovey \& Mayer, 1990). By providing employees with tools and support for their emotional deliberation, managers may be able to deal with 'emotion-related' problems/dilemmas before they escalate into damaging CWBs (e.g. Kwok, Au, \& Ho, 2005).

Our findings are particularly important to national and multinational organizations based in Pakistan, where prior research into these issues has been non-existent. Cultural models suggest that expressions of aggressive emotions and behaviors may be less tolerated in high power distance and collectivist cultures such as Pakistan. A focus on maintaining group harmony and deference to management associated with such cultures may suppress aggressive emotions and behaviors, limiting their influence on key organizational outcomes (Khilji, 2002). Our findings suggest otherwise. It is essential, therefore, that managers working in Pakistani organizations are also aware of the emotional context of work and the potential implications of employees' negative emotions for damaging retaliatory behaviors. 
JUSTICE, EMOTIONS AND COUNTERPRODUCTIVE WORK BEHAVIORS

\section{Conclusion}

Although the attitudinal and behavioral consequences of injustice perceptions are well established, there remains a limited amount of empirical field work exploring the emotional component of organizational injustice. Our findings thus provide further evidence that emotions elicited in response to unfair work events help individuals to appraise the situation at hand and give meaning to these workplace events. These meanings are then manifested in the form of different behaviors (e.g. De Cremer, 2007; Howard \& Cordes, 2010). Our study provides initial evidence that these propositions may hold across different cultural contexts. 
JUSTICE, EMOTIONS AND COUNTERPRODUCTIVE WORK BEHAVIORS

\section{References}

Adams, J.S. (1965). Inequity in social exchange. In L. Berkowitz (Ed.), Advances in experimental social psychology (pp. 267-299). New York: Academic Press.

Allred, K. G. (1999). Anger driven retaliation: Toward an understanding of impassioned conflict in organizations. In R. Lewicki, R. Bies, \& B. Sheppard (Eds.), Research on Negotiation in Organizations (pp. 27-58). Greenwich, CN: JAI Press.

Ambrose, M., Seabright, M., \& Schminke, M. (2002). Sabotage in the workplace: The role of organizational justice. Organizational Behavior and Human Decision Processes, 89, 947965.

Arbuckle, J. L. (1999). AMOS version 16. Chicago: Small Waters Corporation.

Aubé, C., Rousseau, V., Mama, C., \& Morin, E. M. (2009). Counterproductive behaviors and psychological well-being: The moderating effect of task interdependence. Journal of Business and Psychology, 24, 351-361.

Barclay, L. J., Skarlicki, D. P., \& Pugh, S. D. (2005). Exploring the role of emotions in injustice perceptions and retaliation. Journal of Applied Psychology, 90, 629-643.

Bentler, P. M. (1990). Comparative fit indexes in structural models. Psychological Bulletin, $107,238-246$.

Beugré, C. D. (2007). A cultural perspective of organizational justice. New York: Information Age Publishing.

Beugré, C. D. (2005). Reacting aggressively to injustice at work: a cognitive stage model, Journal of Business and Psychology, 20, 291-301.

Bies, R. J., \& Moag, J. F. (1986). Interactional justice: Communication criteria of fairness. In R. J. Lewicki, B. H. Sheppard, \& M. H. Bazerman (Eds.), Research on Negotiations in Organizations Vol. 1 (pp. 43-55). Greenwich CT: JAI Press. 
JUSTICE, EMOTIONS AND COUNTERPRODUCTIVE WORK BEHAVIORS

Bies, R. J., \& Tripp, T. M. (2002). Hot flashes, open wounds: Injustice and the tyranny of its emotions. In S. Gilliland, D. Steiner, \& D. Skarlicki (Eds.), Emerging perspectives on managing organizational justice (pp. 203-221). Greenwich, CT: Information Age Publishing.

Buss, A. H., \& Perry, M. (1992). The aggression questionnaire. Journal of Personality and Social Psychology, 63, 452-459.

Byrne, B. M. (2009). Structural equation modeling with AMOS: Basic concepts, application and programming ( $2^{\text {nd }}$ edition). Oxford: Routledge Academic.

Chebat, J-C., \& Slusarczyk, W. (2005). How emotions mediate the effects of perceived justice on loyalty in service recovery situations: an empirical study. Journal of Business Research, 58, 664-673.

Cheung, G. W., \& Rensvold, R. B. (2002). Evaluating goodness-f-fit indexes for testing measurement invariance. Structural Equation Modeling: A Multidisciplinary Journal, 9, 233-255.

Cohen-Charash, Y., \& Mueller, J. S. (2007). Does perceived unfairness exacerbate or mitigate interpersonal counterproductive work behaviors related to envy? Journal of Applied Psychology, 92, 666-680.

Colquitt, J. (2001). On the dimensionality of organizational justice: A construct validation of a measure. Journal of Applied Psychology, 86, 386-400.

Colquitt, J., Long, D., Rodell, J., \& Halvorsen-Ganepola, M. (2010). Reactions to justice vs. injustice: An inductive study. In J. Colquitt, \& J. Greenberg (Chairs), Are justice and injustice qualitatively distinct concepts? Symposium paper presented at the Society for Industrial and Organizational Psychology, Atlanta.

Cropanzano, R., \& Baron, R. A. (1991). Injustice and organizational conflict: The moderating role of power restoration. International Journal of Conflict Management, 2, 5-26. 
JUSTICE, EMOTIONS AND COUNTERPRODUCTIVE WORK BEHAVIORS

Cropanzano, R., \& Greenberg, J. (1997). Progress in organizational justice: Tunnelling through the maze. In C. Cooper, \& I. Robertson (Eds.), International Review of Industrial and Organizational Psychology, Vol. 12 (pp. 317-372). Chichester: Wiley \& Sons Ltd.

Cropanzano, R., Stein, J. H., \& Nadisic, T. (2011). Social Justice and the Experience of Emotion. New York, NY: Routledge.

De Cremer, D. (2007). Justice and affect: When two friends meet. In D. De Cremer (Ed.), Advances in the psychology of justice and affect (pp. 1-11). Greenwich: IAP.

De Jonge, J., \& Peeters, M. C. (2009). Convergence of self-reports and coworker reports of counterproductive work behavior: A cross-sectional multi-source survey among health care workers. International Journal of Nursing Studies, 46, 699-707.

Diener, E. (2000). Subjective well-being: The science of happiness and a proposal for a national index. American Psychologist, 55, 34-43.

El Akremi, A., Vandenberghe, C., \& Camerman, J. (2010). The role of justice and social exchange relationships in workplace deviance: Tests of a mediated model. Human Relations, 63, 1687-1717.

Fabiani, M., \& Donchin, E. (1995). Encoding processes and memory organization: A model of the Von Restorff effect. Journal of Experimental Psychology: Learning, Memory, and Cognition, 21, 224-240.

Folger, R., \& Cropanzano, R. (2001). Fairness theory: justice as accountability. In J.

Greenberg, \& R. Cropanzano (Eds.). Advances in Organizational Justice (pp. 1-55). Stanford CA: Stanford University Press.

Folger, R., Cropanzano, R., \& Goldman, B. (2005). What is the relationship between justice and morality? In J. Greenberg \& J. Colquitt (Eds.), The Handbook of organizational justice (pp. 215-246). Mahwah: New Jersey: Lawrence Erlbaum Associates.Fox, S., Spector P. E., \& Miles, D. (2001). Counterproductive work behavior (CWB) in response 
JUSTICE, EMOTIONS AND COUNTERPRODUCTIVE WORK BEHAVIORS

to job stressors and organizational justice: Some mediator and moderator tests for autonomy and emotions. Journal of Vocational Behavior, 59, 291-309.

Greenberg, J. (2001a). Studying organizational justice cross-culturally: Fundamental challenges. The International Journal of Conflict Management, 12, 365-375.

Greenberg, J. (2001b). The seven loose cannons of organizational justice. In J. Greenberg \& R. Cropanzano (Eds.), Advances in Organizational Justice (pp. 245-271). Stanford CA: Stanford University Press.

Geddes, D., \& Callister, R. R. (2007). Crossing the line(s): A dual threshold model of anger in organizations. Academy of Management Review, 32, 721-746.

Harmon-Jones, E., \& Sigelman, J. (2001). State anger and prefrontal brain activity: Evidence that insult-related relative left-prefrontal activation is associated with experienced anger and aggression. Journal of Personality and Social Psychology, 80, 797-803.

Hegtvedt, K. A., \& C. Killian: 1999,_Fairness and emotions: Reactions to the process and outcomes of negotiations_, Social Forces, 78, 269-303.

Hofstede, G. (1980). Cultures' consequence: International differences in work-related values. London: Sage.

Hollinger, R. C., \& Clark, J. P. (1983). Theft by employees. Lexington, MA: Heath. Homans, G. (1961). Social Behavior: Its elementary forms. London: Routledge \& Kegan Paul. Howard, L., \& Cordes, C. (2010). Flight from unfairness: Effects of perceived injustice on emotional exhaustion and employee withdrawal. Journal of Business and Psychology, 25, 409-428.

Hu, L., \& Bentler, P. M. (1999). Cutoff criteria for fit indexes in covariance structure analysis: Conventional criteria versus new alternatives. Structural Equation Modeling, 6, 1-55.

Hu, L. T., \& Bentler, P. (1995). Evaluating model fit. In R. H. Hoyle (Ed.), Structural equation modeling: Concepts, issues, and applications (pp.76-99). London: Sage. 
JUSTICE, EMOTIONS AND COUNTERPRODUCTIVE WORK BEHAVIORS

Iacobucci, D. (2008). Mediation Analysis. Thousand Oaks, CA: Sage Publications.

Jensen, J. M., Opland, R. A., \& Ryan, A. M. (2009). Psychological contracts and counterproductive work behaviors: Employee responses to transactional and relational breach. Journal of Business and Psychology, 25, 555-568.

Jones, D. A. (2009). Getting even with one's supervisor and one's organization: Relationships among types of injustice, desires for revenge, and counterproductive work behaviors. Journal of Organizational Behavior, 30, 525-542.

Keltner, D., Ellsworth, P. C., \& Edwards, K. (1993). Beyond simple pessimism: Effects of sadness and anger on social perception. Journal of Personality and Social Psychology, $64,740-752$.

Khan, A. K., (2009). Assessing the dimensionality of organizational justice: Evidence from Pakistani context. Paper presented at the Workshop for Research Advances in Organizational Behavior and Human Resource Management. University of Toulouse, France, May 18 to 20.

Khilji, S. (2002). Modes of convergence and divergence: An integrative view of multinational practices in Pakistan. International Journal of Human Resource Management, 13, 232253.

Kihlstrom, J. F., Eich, E., Sandbrand, D., \& Tobias, B. A. (2000). Emotion and memory: Implications for self-report. In A. A. Stone, J. S. Turkkan, C. A. Bachrach, J. B. Jobe, H. S. Kurtzman, \& V. S. Cain (Eds.), The science of self-report: Implications for research and practice (pp. 81-100). Mahwah, NJ: Erlbaum.

Krehbiel, P. J., \& Cropanzano, R. (2000). Procedural justice, outcome favorability and emotion. Social Justice Research, 13, 339-360. 
JUSTICE, EMOTIONS AND COUNTERPRODUCTIVE WORK BEHAVIORS

Krischer, M., Penney, L., \& Hunter, E. (2010). Can counterproductive work behaviors be productive? CWB as emotion-focused coping. Journal of Occupational Health Psychology, 15, 154-166.

Kwok, C-K, Au, W.T., \& Ho, J.M.C. (2005). Normative controls and self-reported counterproductive behaviors in the workplace in China. Applied Psychology: An International Review, 54, 456-475.

Lazarus, R. S. (1991a). Emotion and adaptation. New York: Oxford University Press.

Lazarus, R. S. (1991b). Progress on a cognitive-motivational-relational theory of emotion. American Psychologist, 46, 819-834.

Lazarus, R. S., \& Cohen-Charash, Y. (2001). Discrete emotions in organizational life. In R. L. Payne, \& G. L. Cooper (Eds.). Emotions at work: Theory, research and applications for management (pp. 45-81). Chichester: John Wiley.

Lee, K., \& Allen, N. J. (2002). Organizational citizenship behavior and workplace deviance: The role of affect and cognitions. Journal of Applied Psychology, 87, 131-142.

Leventhal, G. (1980). What should be done with equity theory? In K. Gregan, M. Greenberg, \& R. Willis (Eds.), Social exchange: Advances in theory and research (pp. 27-55). New York: Plenum.

Mikula, G., Scherer, K. R., \& Athenstaedt, U. (1998). The role of injustice in the elicitation of differential emotional reactions. Personality and Social Psychology Bulletin, 24, 769-783.

Mummendey, A., Kessler. T., Klink, A., \& Mielke, R. (1999). Strategies to cope with negative social identity: Predictions by social identity theory and relative deprivation theory. Journal of Personality and Social Psychology, 76, 229-245.

Neuman, J. H., \& Baron, R. A. (1997). Aggression in the workplace. In R. Giacalone, \& J. Greenberg (Eds.), Antisocial behavior in the workplace (pp. 37-67). Thousand Oaks: Sage. 
JUSTICE, EMOTIONS AND COUNTERPRODUCTIVE WORK BEHAVIORS

Penny, L. \& Spector, P. (2005). Job stress, incivility, and counterproductive work behavior (CWB): The moderating role of negative affectivity. Journal of Organizational Behavior, 26, 777-796.

Rego, A. \& Cunha, M. (2010). Organisational justice and citizenship behaviors: A study in the Portuguese cultural context. Applied Psychology: An International Review, 59, 404-430.

Robinson, M. D., \& Clore, G. L. (2002). Belief and feeling: Evidence for an accessibility model of emotional self-report. Psychological Bulletin, 128, 934-960.

Rotundo, J. L. \& Xie, J. L. (2008). Understanding the domain of counterproductive work behavior in China. International Journal of Human Resource Management, 19, 856-877.

Rupp, D. E., \& Cropanzano, R. (2002). Multifoci justice and social exchange relationships. Organizational Behavior and Human Decision Processes, 89, 925-946.

Salovey, P., \& Mayer, J.D. (1990). Emotional intelligence. Imagination, Cognition, and Personality, 9, 185-211.

Seligman, M. E. P. (1975). Helplessness: On depression, development, and death. San Francisco: W. H. Freeman.

Spector, P. E. (2006). Method variance in organizational research: Truth or urban legend? Organizational Research Methods, 9, 221-232.

Spector, P. E., Fox, S., Penney, L. M., Bruursema, K., Goh, A., \& Kessler, S. (2006). The dimensionality of counterproductivity: Are all counterproductive behaviors created equal? Journal of Vocational Behavior, 68, 446-460.

Spielberger, C.D. (1988). Professional manual for the State-Trait Anger Expression Inventory (STAXI) (research ed.). Odessa, FL: Psychological Assessment Resources.

Spreecher, S. (1992). How men and women expect to feel and behave in response to inequity in close relationships. Social Psychology Quarterly, 55, 57-69. 
JUSTICE, EMOTIONS AND COUNTERPRODUCTIVE WORK BEHAVIORS

Spreecher, S. (1986). The relationship between inequity and emotions in close relationships. Social Psychology Quarterly, 49, 309-321.

Tangney, J. P., \& Dearing, R. L. (2002). Shame and guilt. New York, NY: Guilford Press.

Tangney, J. P., \& Salovey, P. (1999). Problematic social emotions: Shame, guilt, jealousy, and envy. In R. M. Kowalski, \& M. R. Leary (Eds.), The social psychology of emotional and behavioral problems: Interfaces of social and clinical psychology (pp. 167-195). Washington, DC: APA Press.

Thomas, D. L., \& Diener, E. (1990). Memory accuracy in the recall of emotions. Journal of Personality and Social Psychology, 59, 291-297.

Tripp, T. M., Bies, R. J., \& Aquino, K. (2007). A vigilante model of justice: Revenge, reconciliation, forgiveness, and avoidance. Social Justice Research, 20, 10-34.

Van den Bos, K. (2001a). Uncertainty management: The influence of uncertainty salience on reactions to perceived unfairness. Journal of Personality and Social Psychology, 48, 72-81

Van den Bos, K. (2001b). Reactions to perceived fairness: the impact of mortality salience and self-esteem on ratings of negative affect. Social Justice Research, 14, 1-23.

Van den Bos, K., \& Miedema, J. (2000). Toward understanding why fairness matters: the influence of mortality salience on reactions to procedural fairness. Journal of Personality and Social Psychology, 79, 355-366.

Watson, D., \& Clark, L. A. (1994). The PANAS-X manual for the positive and negative affect schedule. University of Iowa.

Weiss, H. M., \& Cropanzano, R. (1996). Affective events theory: A theoretical discussion of the structure, causes and consequences of affective experiences at work. In B. M. Staw, \& L. L. Cummings (Eds.) Research in Organizational Behavior Vol. 18 (pp. 1-74). Greenwich, Conneticut: JAI Press Inc. 
JUSTICE, EMOTIONS AND COUNTERPRODUCTIVE WORK BEHAVIORS

Weiss, H. M., Suckow, K., \& Cropanzano, R. (1999). Effects of justice conditions on discrete emotions. Journal of Applied Psychology, 84,786-794. 


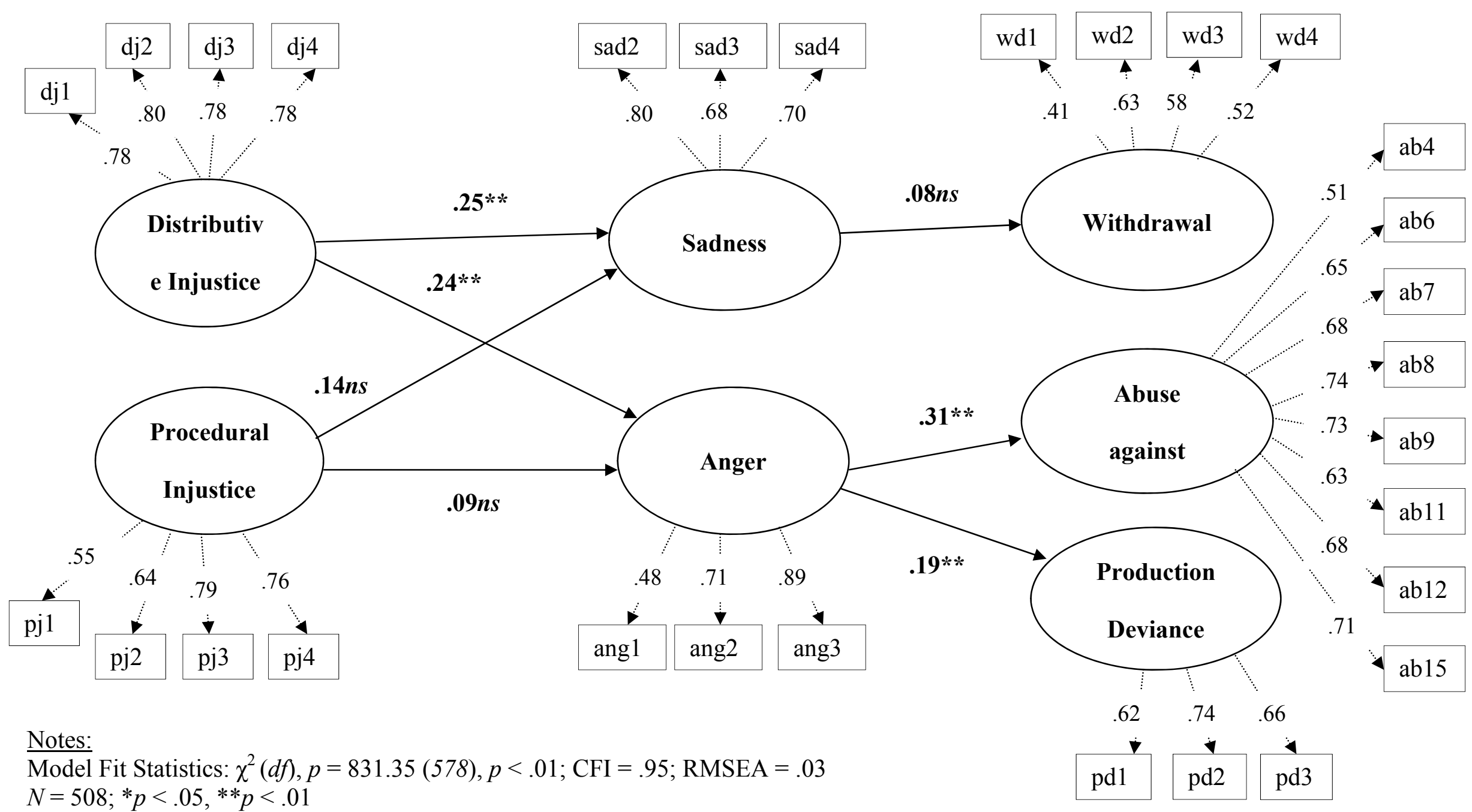

For ease of interpretation, estimates for controls (gender and worksite) are not presented. Organization was not found to be significantly related to any of the dependent variables. Gender was found to be significantly related to anger $(\beta=.08, p<.05)$.

Figure 1. Hypothesized model fit statistics and standardized estimates 
JUSTICE, EMOTIONS AND COUNTERPRODUCTIVE WORK BEHAVIORS

Table 1. Summary of CFA results

\begin{tabular}{lllll}
\hline Model & $\chi^{2}(\boldsymbol{d} f), \boldsymbol{p}$ & CFI & RMSEA & Comparison with 7-Factor Model $\left(\Delta \chi^{2}(\boldsymbol{d} f), \boldsymbol{p}\right)$ \\
\hline Model 1 (3 factor) & $1352.06(375), p<.001$ & .81 & .07 & $651.33(13), p<.01$ \\
Model 2 (4 factor) & $1051.01(373), p<.001$ & .87 & .06 & $350.28(8), p<.01$ \\
Model 3 (5 factor) & $836.46(369), p<.001$ & .91 & .05 & $135.73(4), p<.01$ \\
Model 4 (6 factor) & $796.73(368), p<.001$ & .92 & .05 & $96.00(3), p<.01$ \\
Model 5 (7 factor) & $700.73(365), p<.001$ & .94 & .04 & \\
\hline
\end{tabular}

Note: $\mathrm{N}=508$ 